\title{
TRENDS OF ADOLESCENT CHILDBEARING IN NEPAL - LESSON AND POLICY IMPLICATION
}

Baral K P

\section{ABSTRACT}

\begin{abstract}
Adolescence is a transition period of second decade of life. What happen between age 10-19, whether good or bad, determines how girls and boys live out their lives as adults. In addition to change in social relationship, in Nepal, marriage and child bearing are major events which have direct bearing to the health of adolescents. Fertility among adolescents in Nepal is high compare to develop countries and Nepal Family Health Survey 2001 reported that only $\mathbf{5 9 . 6}$ percent married adolescent had no children. It was found that during 5 years period there is slight decrease in the prevalence of adolescent childbearing in Nepal. The best way to prevent adolescent pregnancy, as long-term measure, is by providing opportunities specially for education and skills development through which their status increases. It is equally important to focus family planning services and reproductive health education through health program to them.
\end{abstract}

Key Words: Adolescent, adolescent childbearing, fertility, and contraceptive.

\section{INTRODUCTION}

Adolescent childbearing is an aged old problem in Nepal. Only in the later part of the 20th century, knowledge on its consequences emerged as an issue of public health concern. Awareness about the early childbearing and its health risk for the mother and the child and impact on country's fertility is growing in Nepal. In addition to health risks, it hampers further education of female adolescents and consequently earning capacity and overall well being. ${ }^{1}$ It has a wide spectrum of impact. At the personal level, early marriage and child bearing or early age of child bearing retards potentials for growth and development of adolescents. Her care giving capacity to the child is also not enough to provide physical and psychological support optimally require by a child. This reflects in the society in such a way that females have less capacity and consequently pushed into a lower position in all the spheres of societal life. The other important factor for the rapid population growth is early childbearing i.e. before the age of twenty. ${ }^{2,3}$ The rapid population growth has negative impact on the national development because of limited resource sharing among growing population.

The adolescent period covers the age of 10-19 years. ${ }^{4}$ This is a period of transition from childhood to adulthood. It coincides with the second decade of life. What happens between the age of 10-19, whether good or bad, determines how girls and boys live out their lives as adult females and males- not only in the context of reproductive health but also in the social and economic environment in society. Adolescent childbearing and having a baby and its consequences depends on the context where she belongs like culture, familial and community setting but health consequences for mother and child is the problem recognized universally. 5,6

The age below which the risk of childbearing is considered to be significant varies depending on health and nutrition conditions of adolescent and access to health care specially obstetrical care. In a country where prevalence of micronutrients (specially anemia and Vitamin A) deficiency

Address for correspondence : $\quad$ Dr. Kedar P. Baral

PLAN Nepal, Kathmandu, Nepal.

Email: kedar.baral@plan-international.org 
and malnutrition specially chronic energy deficiency is very high and access to healthcare is not optimal, the risks are enormous. On the other hand, if the health and nutritional status of females is good the risks also minimal. ${ }^{7}$ The development during adolescent is rapid the risks of childbearing are high among the younger age group. Adolescent child bearing is associated with early marriage and low level of contraceptive prevalence rate. Therefore, early marriage and adolescent child bearing is important for the overall fertility level and growth and development of mother and child.

Early marriage and childbearing is prevalent in Nepal like in Indian, Bangladesh, Pakistan and other African countries. ${ }^{8}$ In Nepal adolescent comprises of $23 \%$ out of 23 million population. ${ }^{9}$ The median age at first marriage for ever married women in Nepal age 15-49 is 16.6 years, which indicates majorities of newly married couples are adolescents. ${ }^{10}$ They comprise the fertility potential cohort in Nepal. One of the objectives of 10th Five Year Plan ${ }^{11}$ is population management. To achieve this objective, it is essential to manage fertility of this cohort. Therefore, it is important to understand the adolescent fertility in order to develop appropriate programs. This study examines the trends, levels and distribution in term of ecological, regional and educational aspect of fertility among adolescents.

\section{DATA AND METHODOLOGY}

The data used in this study is from Nepal Family Health Survey $1996^{12}$ which is equivalent to Demographic and Health Survey (later referred Demographic and Health Survey 1996) and Nepal Demographic and Health Survey 2001. Based on these two surveys the trends of adolescent fertility has been compared and presented. A total of 2,229 and 2,335 adolescents between 15-19 years of age participated in 1996 and 2001 NDHSs

Table I : Percentage of all females (ever-married never-married) aged 15-19 years who are mothers or pregnant with their first child with selected characteristics

\begin{tabular}{l|ccc|c|c|c|cc}
\hline \multirow{2}{*}{$\begin{array}{c}\text { Background } \\
\text { Characteristics }\end{array}$} & \multicolumn{3}{|c|}{$\begin{array}{c}\text { Percentage who are: } \\
\text { Mothers }\end{array}$} & \multicolumn{4}{c|}{$\begin{array}{c}\text { Percentage who } \\
\text { Pregnant with first } \\
\text { child }\end{array}$} & \multicolumn{2}{c}{$\begin{array}{c}\text { Number of } \\
\text { have begun } \\
\text { childbearing } \\
\text { adolescent }\end{array}$} & & \\
Age & $\mathbf{1 9 9 6}$ & $\mathbf{2 0 0 1}$ & $\mathbf{1 9 9 6}$ & $\mathbf{2 0 0 1}$ & $\mathbf{1 9 9 6}$ & $\mathbf{2 0 0 1}$ & $\mathbf{1 9 9 6}$ & $\mathbf{2 0 0 1}$ \\
\hline 15 & 1.1 & 0.5 & 2.1 & 1 & 3.2 & 1.5 & 458 & 361 \\
\hline 16 & 6.4 & 3.9 & 5.4 & 5.4 & 11.8 & 9.3 & 469 & 451 \\
17 & 15 & 12.6 & 7.8 & 4.9 & 22.8 & 17.5 & 428 & 571 \\
\hline 18 & 31.2 & 25.3 & 4.8 & 8.8 & 36 & 34 & 449 & 510 \\
19 & 44.1 & 35.9 & 6.6 & 4.6 & 50.7 & 40.5 & 399 & 442
\end{tabular}

Residence

\begin{tabular}{l|ccc|c|c|c|cc}
\hline Urban & 15.5 & 10.1 & 4.2 & 2.5 & 19.7 & 12.6 & 173 & 249 \\
Rural & 18.9 & 17 & 5.3 & 5.5 & 24.3 & 22.5 & 2054 & 2087 \\
\hline Ecological region \\
\hline Mountain & 14.8 & 15.8 & 5.6 & 3.9 & 20.4 & 19.7 & 148 & 157 \\
Hill & 13.1 & 12.1 & 3.9 & 4.9 & 16.9 & 17 & 1036 & 1041 \\
\hline Tarai & 24.6 & 20 & 6.5 & 5.6 & 31.1 & 25.5 & 1052 & 1144
\end{tabular}

Development region

\begin{tabular}{l|ccc|c|c|c|cc} 
Eastern & 15.3 & 16.5 & 4.5 & 6.1 & 19.8 & 22.6 & 537 & 579 \\
\hline Central & 22.2 & 19.5 & 6.2 & 4.3 & 28.5 & 23.8 & 725 & 677 \\
Western & 15.5 & 11.9 & 3.3 & 4.2 & 18.8 & 16.1 & 457 & 501 \\
\hline Mid-Western & 19.5 & 16.2 & 7.6 & 5.8 & 27 & 22 & 297 & 354 \\
\hline Far-Western & 20.3 & 15.5 & 4.7 & 7 & 25.1 & 22.5 & 217 & 220
\end{tabular}

Education

\begin{tabular}{l|ccc|c|c|c|cc}
\hline No education & 25 & 24.9 & 6.8 & 6.6 & 31.8 & 31.5 & 1123 & 842 \\
\hline Primary & 17.2 & 14.3 & 5.1 & 5.3 & 22.3 & 19.6 & 497 & 662 \\
\hline Secondary & 7.3 & 9.7 & 2.3 & 3.6 & 9.6 & 13.2 & 672 & 706 \\
\hline $\begin{array}{c}\text { SLC and above } \\
\text { Total }\end{array}$ & & 4.3 & & 4 & & 8.3 & & 138 \\
\hline
\end{tabular}


surveys respectively. In this study, age-specific fertility rate and proportion of females who have had child by specific age have been presented. The first measure is commonly used to find the current incidence of childbearing in recent period. The second measure describes the timing of early childbearing because it measures percent of adolescent having one or more births by specific age. The second measure is $20-24$ and older, as these age groups provide description of childbearing for completed period of adolescent. In addition contraceptive use focusing among adolescent has also been presented.

\section{RESULTS}

\section{Adolescent pregnancy and motherhood}

Table I shows the percentage of all females (never-married and ever married) aged 15-19 years who were mothers or pregnant with their first child and their distribution in urban and rural locations, ecological and development regions and educational status. It is noted that there is steady decrease of adolescent who have begun childbearing. In 199623.9 percentage have begun childbearing and after 5 years it decrease to 21.4 percent. The decrease in two surveys among 15 -year adolescent was more than half from 3.2 percent in 1996 to 1.5 percent in 2001 . The percentage point reduction among 16, 17, and 18 is in between 2 to 5.3 but aged 19 rose to 10.2. Furthermore, the reduction was sharp in urban from
19.7 to 12.6 percent but in rural area 2.2 percent point only. By ecological region, Tarai shows 5.6 percentage point reduction where 48 percent of population inhabitants and negligible change in Mountainous and Hill regions. By development region, Central and Mid-Western region are ahead than other regions and no education group remains almost the same percent with only 0.3 percent point reduction.

\section{Fertility}

Table II shows that in Nepal there is steady reduction of fertility between 1984-86 to 1998-2000 from 5.11 to 4.1. Among adolescents between 15-19 years of age, in 1993-95 127 births per 1,000 15-19 years adolescent and 1998-2000 it reduced to 110. In Nepal it is estimated that a women bears 4.1 children by the end of her reproductive age and 0.11 per adolescent. The highest contribution to the total fertility rate was by women of 20-24 age group. It is noted that adolescent fertility has not been reducing and rate of 1998-2000 is higher than the rate of 1984-86 and 1989-91 suggesting that compare to total fertility adolescent fertility remains high and has little or no contribution to the total reduction.

\section{Childbearing}

The table III shows proportion of all women including those never married in different age cohorts who had a child by specific age during adolescent period indicates a high incidence

Table II : Trends of Age-specific Fertility Rates in Nepal from 1984 through 2000

\begin{tabular}{ccc|cc}
\hline Age group & $\mathbf{1 9 8 4 - 8 6}$ & $\mathbf{1 9 8 9 - 9 1}$ & $\mathbf{1 9 9 3 - 9 5}$ & $\mathbf{1 9 9 8 - 2 0 0 0}$ \\
$15-19$ & 99 & 101 & 127 & 110 \\
$20-24$ & 261 & 263 & 266 & 248 \\
\hline $25-29$ & 230 & 230 & 229 & 205 \\
\hline $30-34$ & 200 & 169 & 160 & 136 \\
$35-39$ & 114 & 117 & 94 & 81 \\
\hline $40-44$ & 68 & 55 & 37 & 34 \\
\hline $45-49$ & 49 & 26 & 15 & 7 \\
\hline TFR & $\mathbf{5 . 1 1}$ & $\mathbf{4 . 7 9}$ & $\mathbf{4 . 6 4}$ & $\mathbf{4 . 1}$ \\
\hline
\end{tabular}

Source: Nepal Demographic and Health Survey 2001 table 4.3

Table III : Among all women who have given birth, percentage who had their first birth by specific ages, and median age at first birth, by current age, Nepal 2001

\begin{tabular}{|c|c|c|c|c|c|c|c|c|}
\hline \multirow{2}{*}{$\begin{array}{c}\text { Current } \\
\text { age group }\end{array}$} & \multicolumn{5}{|c|}{ Age at first birth } & \multirow{2}{*}{$\begin{array}{c}\text { Percentage who } \\
\text { have never } \\
\text { given birth }\end{array}$} & \multirow{2}{*}{$\begin{array}{l}\text { Median age } \\
\text { at first birth }\end{array}$} & \multirow{2}{*}{$\begin{array}{l}\text { Number } \\
\text { of women }\end{array}$} \\
\hline & 15 & 18 & 20 & 22 & 25 & & & \\
\hline $20-24$ & 0.8 & 26 & 51.3 & & & 29.5 & 19.9 & 2001 \\
\hline $25-29$ & 1.3 & 24 & 54.1 & 75.2 & 88.5 & 8.3 & 19.7 & 1744 \\
\hline $30-34$ & 0.9 & 23.8 & 51.5 & 74 & 87.9 & 4.5 & 19.9 & 1464 \\
\hline $35-39$ & 1.3 & 24.1 & 50.2 & 70.6 & 87.4 & 4.2 & 20 & 1191 \\
\hline $40-44$ & 1.0 & 23.7 & 50.1 & 70.6 & 86.9 & 2.9 & 20 & 1042 \\
\hline $45-49$ & 1.2 & 23.7 & 47.5 & 69.8 & 87.4 & 3.1 & 20.2 & 849 \\
\hline
\end{tabular}

Source: Nepal Demographic and Health Survey 2001 table 4.8 
of early child bearing in Nepal. Median age at first birth is about 20 years across all age cohorts suggesting no change in the age at first birth. Around one percent of women given birth by the age of 15 and around 25 percent have had birth by the age of 18. In Nepal by the age of 2047.5 to 54.1 percent women in different age cohorts gave their first birth. Around 70 percent gave birth by the age of 22 and it reached to almost 90 percent by the age of 25 years. The table 3 shows that there is no raise of age at first birth among younger and older age cohorts but slightly decreased median age at first birth among younger age cohorts. One of the ways of analyzing the trends of adolescent childbearing is by using the proportion of women who had a child by age of 20 and comparing it with older aged women. It has been noted that in Nepal the percentage of women of age at first birth have not much changed in comparison with 20-24 years and older women.

Table IV presents the percentage distribution of all adolescents and currently married adolescents aged 15-19 by number of ever-born, living and mean number of children. Among currently married adolescent 34.1 percent in 1996 and 35.4 percent in 2001 had one child. But adolescent with two or more children ever born sharply reduced by almost half percent point. On the other hand among all adolescent the percent point decreased slightly as shown in the table IV. In 199657.3 percent and in 200159.6 percent married adolescent had no children. It is noted that mean number of children ever born in both, all and married adolescents, had decreased and more among married with 0.6 percent point.

\section{Contraceptive use}

In addition to the female literacy, exclusive breast-feeding and age at marriage, use of contraceptive is extremely important for fertility management. NDHS 2001 reported that contraceptive prevalence rate for Nepal is 39.3 percent (any method, currently married women). Therefore, for those unmarried adolescents we do know the rate. Table 6 presents the distribution of contraceptive use rate by age group and only 12 of married adolescent were using contraceptive during survey of NDHS 2001.

It is important to know the timing of initial family planning use in relation to childbearing. NDH 2001 included a question for ever married woman who had ever used contraception and enquired the number of living children they had at the time of first use. Table VII shows that younger women reported first use at lower parities than older women. 58.4 percent adolescent age 15-19 had initiated who have ever used family planning

Table IV : Percentage distribution of adolescent aged 10-19 years by children ever born

\begin{tabular}{c|c|c|cc|c|c|cr}
\hline $\begin{array}{c}\text { Children } \\
\text { Ever born }\end{array}$ & \multicolumn{2}{|c|}{ All adolescent } & \multicolumn{2}{|c|}{$\begin{array}{c}\text { Mean number of } \\
\text { children ever born }\end{array}$} & \multicolumn{2}{|c|}{$\begin{array}{c}\text { Mean number of } \\
\text { living children }\end{array}$} & \multicolumn{2}{|c|}{$\begin{array}{c}\text { Number of } \\
\text { adolescent }\end{array}$} \\
\hline \multirow{2}{*}{} & $\mathbf{1 9 9 6}$ & $\mathbf{2 0 0 1}$ & $\mathbf{1 9 9 6}$ & $\mathbf{2 0 0 1}$ & $\mathbf{1 9 9 6}$ & $\mathbf{2 0 0 1}$ & $\mathbf{1 9 9 6}$ & $\mathbf{2 0 0 1}$ \\
0 & 81.3 & 83.8 & & & & & & \\
1 & 14.9 & 14.3 & \multirow{2}{*}{0.23} & 0.18 & 0.21 & 0.16 & 2229 & 2335 \\
\cline { 1 - 2 } 2 & 3.5 & 1.9 & & & & & &
\end{tabular}

Currently married adolescent

\begin{tabular}{|c|c|c|c|c|c|c|c|c|}
\hline 0 & 57.3 & 59.6 & \multirow{4}{*}{0.52} & \multirow{4}{*}{0.46} & \multirow{4}{*}{0.47} & \multirow{4}{*}{0.41} & \multirow{4}{*}{965} & \multirow{4}{*}{930} \\
\hline 1 & 34.1 & 35.4 & & & & & & \\
\hline 2 & 8.1 & 4.7 & & & & & & \\
\hline 3 and more & 0.6 & 0.3 & & & & & & \\
\hline
\end{tabular}

Source: Nepal Demographic and Health Survey 2001 table 4.6

Nepal Family Health Survey 1996 table 3.7

Table V : Percent distribution of currently married women by contraceptive currently used, Nepal 2001

\begin{tabular}{cc|cc|c}
\hline $\begin{array}{c}\text { Age } \\
15-19\end{array}$ & $\begin{array}{c}\text { Any method } \\
12\end{array}$ & $\begin{array}{c}\text { Any modern method } \\
9.3\end{array}$ & $\begin{array}{c}\text { Not currently using } \\
88\end{array}$ & $\begin{array}{c}\text { Number of women/men } \\
\text { 20-24 }\end{array}$ \\
23.4 & 20.7 & 76.6 & 1643 \\
$25-29$ & 40.1 & 35.5 & 59.9 & 1625 \\
\hline $30-34$ & 53.5 & 48 & 46.5 & 1377 \\
\hline $35-39$ & 56.2 & 51.8 & 43.8 & 1099 \\
\hline $40-44$ & 51.9 & 47.8 & 48.1 & 936 \\
\hline $45-49$ & 40 & 36.9 & 60 & 732 \\
\hline
\end{tabular}

Source: Nepal Demographic and Health Survey 2001 part of the table 5.3 
Table VI : percentage distribution of women who have ever used contraceptive by number of living children at the time of first use of contraception, according to current age, Nepal 2001

\begin{tabular}{cc|cc|c|cc}
\hline Current age & \multicolumn{8}{c}{ Number of living children at the time of first use of contraceptive } & Number of women \\
& $\mathbf{0}$ & $\mathbf{1}$ & $\mathbf{2}$ & $\mathbf{3}$ & $\mathbf{4}$ & \\
$15-19$ & 58.4 & 36.3 & 5.3 & & & 204 \\
\hline $20-24$ & 18.2 & 52.7 & 21.9 & 6.7 & 0.5 & 703 \\
\hline $25-29$ & 5.4 & 30.2 & 29.6 & 24.1 & 10.7 & 948 \\
$30-34$ & 2.1 & 20 & 24.7 & 25.1 & 28.2 & 951 \\
\hline $35-39$ & 1.9 & 11.3 & 17 & 26.4 & 43.4 & 765 \\
\hline $40-44$ & 0.7 & 7.8 & 14.2 & 20.8 & 56.5 & 639 \\
\hline $45-49$ & 0.6 & 7.1 & 10.5 & 21.8 & 60.1 & 426 \\
\hline
\end{tabular}

Source: Nepal Demographic and Health Survey 2001 table 5.7

before having any children. It is noted that there is increasing trends to initiate to use family planning before having children in Nepal.

\section{Lesson and policy implications}

The present National Adolescent Health and Development Strategy ${ }^{13}$ is comprehensive and the main objectives are 1 . To increase the availability and access to information about adolescent health and development, and provide opportunities to build skills of adolescents, service providers and educators.

2. To increase accessibility and utilization of adolescent health and counseling services for adolescents, and 3 . To create safe and supportive environments for adolescents in order to improve their legal, social and economic status. The present policy spans health to wider social dimensions. For meeting these objectives program should be tailored to specific age and other characteristics like socio-economic status, ethnicity, rural urban location and literacy, adolescent in school and community. Adolescents' involvement in the program cycle is crucial specially for ownership and sustainability. It should be sensitive to the different needs of girls and boys and must be built from bottom up. The size of population, potential of adolescent for future responsible citizen and parenthood should be the reasons for the investment in the program. There should be space for female adolescent in all the development programs. The programs of adolescent reproductive health should not only dispense information to the unmarried but for all. It would not be sufficient to focus narrowly on knowledge on reproductive physiology and methods to avoid pregnancy and STIs and HIV/AIDS. Role of male partners and family members to support the program is important, as they are decision-makers who impose what is good and bad for them.

In view of high incidence of adolescent childbearing in Nepal, appropriate programmatic approach has to be undertaken as soon as possible to reduce the incidence of early childbearing that have negative health, social and economic consequences, including educational achievement and job prospects of the generation. In order to reduce the rate of early childbearing, adolescents, their parents and the community should be sensitized and made more aware of the negative health, social and economic consequences of early marriage and early childbearing. An approach will be to create awareness through social mobilization, and behavioral change communication combined with campaigns. Early childbearing can be postponed by delaying early marriage. There is little evidence the effectiveness of legislating alone the age at marriage in delaying early marriage because of the prevailing cultural and social norms favoring early marriage. Therefore, needs to adopt other strategies such as policy and programs to increase the opportunities for education, empowerment in decision making, micro finance and income generation and employment outside home, all of which are likely to result in delayed marriage. More important and sort-term measure is needed to extend the interval between marriage and the first birth. This will delay the timing of the first birth through the effective use of family planning methods. There is evidence that, in most developing countries, adolescent face difficulty in obtaining family planning methods due to lack of knowledge and also limited access to family planning services. ${ }^{14}$ The current contraceptive prevalence rate among adolescent in Nepal suggests that it requires more programmatic effort focusing adolescents especially on newly married couples. An appropriate approach would be adolescent friendly health services building on the existing network of health system.

Adolescence is a distinct and important biological and social stage of development. There is inadequate recognition of this period as a critical stage of growth and development within the life cycle. The vulnerability of adolescents female heightens due to biological and social reasons and they are more prone not only pregnancy and child bearing but also to diseases and conditions specially STI's, substance abuse and accident. Nepali society pays more attention preparing female adolescent for 
marriage and motherhood roles rather then on education and life skills development.

We need diverse initiatives that improve the present condition of girls. It is not to over emphasize that gender is a cross cutting problem in Nepal and the face of gender is different in different geographical areas and ethnic groups.

The best way for prevention of adolescent pregnancy is by providing opportunities through which their social status increases. The opportunity for education and skills development is needed not merely to provide reproductive health information and family planning services. The goal for the program should be overall growth and development and not only limited to control of HIV transmission and fertility among adolescent.

\section{ACKNOWLEDGMENT}

I would like to thank Dr. Babu Ram Marasini for his constructive comments which helped to bring the final shape of this article.

\section{REFERENCES}

1. United Nations. The World's Women, 1995: Trends and Statistics. (New York, United Nations) . 1995.

2. Senderowitz and Paxman. Adolescence fertility: Worldwide Concem. Population Bulletin. 1985; 40 (2) : 3-51.

3. Mazur, Laurie Ann. High Stakes: The United States, Global Population and our common Future (New York, The Rockefeller Foundation) . 1997.

4. WHO. Young people's health-A challenge for society. Report of a WHO Study Group on Young People and "Health for All by the Year 2000". Geneva, World Health Organization, (WHO Technical Report Series No. 731) . 1986.

5. Buvinic, Mayra and Kathleen Kurz. Prospect of young mothers and their children: a review of the evidence on consequences of adolescent childbearing in developing country. Paper presented at the committee on population, National Research Council, National Academy of Sciences Workshop on adolescent Reproduction in Developing Countries, Washington DC, 1998.

6. Acsadi, George T. F. and Gwendolyn Johnson-Acsadi. Optimum conditions for Childbearing (London, International Planned Parenthood Federation) . 1986.

7. Makinson, Carolyn. The health consequences of teenage fertility. Family Planning Perspectives. 1985; 17 (3) : 132-139.

8. Barbara S. Mensch, Judith Bruce and Margaret E. Greene. The Uncharted Passage: girls adolescence in the developing world. The population Council, Inc. (One Day Hammarskjold Plaza, New York) . 1998.

9. Central Bureau of Statistics (CBS) . Population Census 2001 National Report. HMG/Nepal National Planning Commission Secretariat Central Bureau of Statistics in collaboration with UNEPA Nepal, Kathmandu. 2002.

10. Ministry of Health (Nepal), New ERA, and ORC Macro. Nepal Demographic and Health Survey 2001. Calverton, Maryland, USA: Family Health Division, Ministry of Health; New ERA; and ORC Macro. 2002.

11. His Majesty Government of Nepal, National Planning Commission (NPC) (2002). The Tenth Plan Approach Paper. www. Npc.np/tenthplan/_-_/approach (accessed on 20/2/ O4).

12. Pradhan, Ajit, Ram Hari Aryal, Gokarna Regmi, Bharat Ban, and Pavalavalli Govindasamy. Nepal Family Health Survey 1996. Kathmandu, Nepal and Calverton, Maryland: Ministry of Health (Nepal), New ERA, and Macro International Inc. 1997.

13. MOH (Nepal) Department of Health Services Family Health Division. National Adolescent Health and Development Strategy. Family Health Division, Kathmandu. 2000.

14. Blanc, Ann K., Ann A. Way. Contraceptive knowledge and use and sexual behavior: a comparative study of adolescents in developing countries. Studies in Family Planning. 1998; 29 (2) : 106-116.

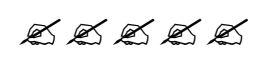

